\title{
Conflicto, dominación y violencia
}

doi: http://dx.doi.org/10.32870/espiral.v24i68.6333.g5643

Jorge Alonso Sánchez*

El doctor en Historia Carlos Illades ha publicado varios libros sobre el artesanado mexicano en el siglo XIX, la formación del pensamiento socialista en México y la que llamó "la inteligencia rebelde", en donde explora el pensamiento social y político de la izquierda mexicana y latinoamericana. Ha escrito también sobre el anarquismo posmoderno del siglo XXI. Se puede decir que el libro que aquí se reseña es una continuación de sus investigaciones en esas líneas.

Conflicto, dominación y violencia es un libro en el que a movimientos sociales diversos y dispersos en la geografía y tiempo de México el autor les va encontrando coherencia por medio de las herramientas de la historia social. Tomó como guía hermenéutica los conceptos de dominación, violencia y conflicto. Indagó las resistencias, la organización y la acción colectiva en el medio artesanal del siglo XIX, constató cómo se fue formando la conciencia de una emergente y compleja clase obrera y el impacto de las rebeliones agrarias que llegan hasta nuestros días, profundizó en los ciclos de la violencia social en el estado de Guerrero y exploró las manifestaciones del neoanarquismo en el siglo XXI. Exploró las sociabilidades tradicionales y modernas. Constató que tanto las movilizaciones populares como las represiones estatales han sido algo constante.

Carlos Illades (2015). Conflicto, dominación y violencia. México: Gedisa. 
Hay un capítulo de discusión teórica en el que hace una revisión de planteamientos de diversos autores para comprender la historiografía de los movimientos sociales que han sido investigados tanto por historiadores como por sociólogos, y cómo ambos acercamientos han tenido que realizar trabajo interdisciplinar. Llama la atención sobre que no hay que confundir las formas de acción colectiva con las ocasiones en que estas ocurren. Convoca a no simplificar la diversidad. Combina tanto perspectivas que destacan los elementos estructurales que hacen posibles los movimientos sociales como las que permiten apreciar los mecanismos específicos y complejos que disparan la acción colectiva y hacen que esta ocurra en determinado punto espacio-temporal.

Otro capítulo se centra en la organización y acción colectiva del artesanado contextualizando su participación en el siglo XIX mexicano. Presenta con gran detalle el desarrollo del Gran Círculo de Obreros en México, su involucramiento político en la época juarista y posterior. Plantea que la intervención política partidaria acabó con esta organización. Lleva al lector por las huelgas de sastres, sombrereros y tipógrafos hasta llegar a las clásicas huelgas de Cananea y Río Blanco, a inicios del siglo XX. Prosigue su rastreo de las huelgas y destaca la textil en el periodo maderista. Recuerda que la Casa del Obrero Mundial reunía canteros, textileros, sastres, cocheros y otros, y cómo pactó con el constitucionalismo para oponerse al villismo y zapatismo. Nos hace ver que el año de 1915 fue especialmente movido por las huelgas de canteros, empleados de restaurantes, conductores de carruajes de alquiler, sastres, tranviarios y electricistas; poco después, las hubo de trabajadores de artes gráficas y panaderos. Apunta que diversos gremios se fueron sindicalizando. En este rastreo, destaca la huelga general de la Federación de Sindicatos del Distrito Federal. Cuando el constitucionalismo aplastó al villismo y al zapatismo, sus 
aliados en el ámbito del trabajo fueron un estorbo porque no le gustaban las huelgas. Posteriormente, Obregón optó con la cooptación (y corrupción de líderes) y se afianzó en la CROM con el dirigente Morones.

El autor dedica otro capítulo a rebeliones agrarias en la segunda mitad del siglo XIX, provocadas en gran parte por la desamortización de la propiedad comunal y la expansión de las haciendas a costa del despojo de tierras de los pueblos. Rastrea una rebelión que tuvo objetivos socialistas. Estudia pormenorizadamente la Confederación Mexicana Socialista y la rebelión de los Pueblos Unidos en los estados de Querétaro y Guanajuato, en 1879. El autor considera que este proceso sentó las bases del agrarismo que se desarrollaría en la Revolución mexicana y que existe un continuo histórico de resistencias y luchas que va desde entonces hasta el zapatismo chiapaneco que irrumpió en 1994 y lo que se ha venido expresando en la lucha de los pueblos indígenas y campesinos contra el despojo neoliberal y extractivista en lo que va del siglo XXI.

Hay un tratamiento que podríamos considerar como contrapunto a la dinámica que posee el libro y que se refiere a las fracturas étnicas y sociales que afloraron durante la Revolución en la interacción entre los ejército populares y las colonias extranjeras, en particular con la más numerosa, la hispana, la cual ocupaba nichos económicos sensibles para la población de escasos recursos. En este apartado se trata la política migratoria y de colonización promovida por el régimen liberal. Se resaltan los rasgos económicos y sociales de los españoles en la Ciudad de México. Se hacen cuantificaciones de las reclamaciones en torno a daños sufridos por la colonia española durante la época revolucionaria. Se destaca que en el roce de las tropas y los residentes hispanos influía la herida abierta por tres siglos de dominación colonial que agregó un ingrediente adicional de violencia. También influyó el que los estratos más altos 
de los españoles residentes habían hecho una alianza con el porfirismo. En este contexto se ubica el apoyo del Estado Español a Huerta. Posteriormente, con el constitucionalismo la tensión se fue diluyendo.

Un capítulo más da seguimiento a cómo se inició y se fue desarrollando la ciencia social en México desde finales del siglo XIX hasta inicios de la segunda mitad del siglo XX. Se remonta al positivismo porfirista. Se da cuenta de cómo en los albores del siglo XX se empezó a echar mano de la sociología y fueron avanzando los estudios históricos. Apareció la importancia de la antropología. Se desemboca en el estudio clásico de Pablo González Casanova que realiza una explicación científica por parte de mexicanos del funcionamiento del sistema político mexicano. Se iniciaron y ampliaron los estudios de los problemas nacionales por parte de estudiosos mexicanos en ámbitos académicos nacionales.

Este recuento es como un preludio para el capítulo sexto en el que se profundiza en lo que denomina el círculo de la violencia. En la segunda mitad del siglo XX, muchos movimientos reivindicaron libertades básicas y derechos sociales elementales. La respuesta estatal fue la represión. Algunos movimientos fueron orillados hacia la respuesta armada, aunque hubo vertientes que demandaron democracia frente al autoritarismo del Estado. El autor apunta la hipótesis de que en los puntos críticos de la geografía nacional el ciclo de la violencia se desataba en los periodos de ascenso de los movimientos sociales ante los cuales el Estado, con la base local y regional de cacicazgos, respondía con la cooptación o represión. Se fueron dando movimientos que desarrollaron formas de autodefensa, y algunos llegaron a expresiones guerrilleras que se propusieron la toma del poder.

El autor se centra en el caso del estado de Guerrero. Se remonta hasta el Partido Obrero en Acapulco, pasa por el Partido de los Pobres de Lucio Cabañas, llega a la masacre de Aguas Blancas, para aludir después al Ejército Popular 
Revolucionario. Hay expresiones de autodefensa que no se plantean la toma del poder, sino hacerse cargo de asegurar justicia y seguridad ante la ausencia de las funciones que corresponderían al Estado. Se hace ver que en 2014 en más de la mitad de los municipios guerrerenses había autodefensas. Se toca el punto de los crímenes de Iguala, en septiembre de 2014, y la indignación social que emergió con gran fuerza. Ese acontecimiento reveló que la delincuencia y la política estaban imbricadas, y que la representación supuestamente democrática había sido secuestrada por el crimen organizado. El autor sostiene que en esa entidad federativa hay un continuo de movilización-represiónautodefensa que ha cumplido varios ciclos.

El siguiente capítulo se adentra aún más en la relación entre violencia y protesta pública. Destaca el autor que la acción de la multitud tiene objetivos específicos. Precisa que en la época preindustrial la violencia iba contra las cosas y ocasionalmente contra las personas, y que posteriormente la clase obrera hizo de la manifestación callejera el espacio de su expresión colectiva. Apunta que en la segunda mitad del siglo XX empezaron a sumarse otros grupos a los clásicos movimientos sociales. Con la reestructuración económica del capitalismo globalizado y el fin del Estado neoliberal en la expresión del neoliberalismo, el autor constata que ha renacido la multitud en el siglo XXI.

Citando a Hardt y Negri, la ve como ese sujeto intermitente, difuso y múltiple, cuya acción no responde a identidades, sino a lo que existe en común. Focaliza el autor a núcleos minoritarios violentos dentro de esa multitud. Específicamente, explora el llamado black bloc que se ha venido expresando en Europa, Chile, Brasil y México. Hace saber que es una táctica de lucha que han desarrollado los neoanarquistas, pero no sólo ellos. Se trata de grupos de afinidad que avanzan y retroceden coordinadamente, en donde cada uno tiene una tarea particular, donde no hay 
líderes ni límites. Son grupos de choque de autodefensa que actúan dentro del campo popular.

El autor realiza una genealogía del black bloc en el mundo y destaca sus expresiones de los últimos tiempos en México. Se dedican a romper cristales o destruir cajeros automáticos de los que sacan dinero para repartir entre la gente. Nos dice el autor que la violencia encontró terreno fértil en algunos grupos que se radicalizaron en la huelga estudiantil de 1999 en la UNAM. Detecta expresiones de los neoanarquistas en la Asamblea de los Pueblos de Oaxaca en 2006. Indaga que en las protestas recientes en la Ciudad de México tienen participación el Frente Popular Revolucionario, el Frente Oriente y algunos grupos más. Precisa el autor que no todos los grupos tienen afinidad ideológica, pues algunos se dicen comunistas, otros ambientalistas, otros anarquistas o pertenecen a diversas banderías. Con su detallada investigación, el autor detecta que proceden del oriente de la Ciudad de México y la conurbación mexiquense. Recapitula que en 2011 medio centenar de acciones se atribuyeron a células autónomas de Inmediata Revolución Práxedis G. Guerrero, al Frente de Liberación Animal, al Frente de Liberación de la Tierra y a algunos más. Se han expresado actos de solidaridad con otros anarquistas en el mundo.

Aunque esas acciones enlistadas se expresaron en ocho estados del país, el $42 \%$ se dieron en la Ciudad de México y el $27 \%$ en el Estado de México. El núcleo más activo de ese universo de neoanarquistas se conjunta en la organización de Células Autónomas de Revolución Inmediata. Las acciones tienen que ver con sabotajes, explosivos y otras actividades de acción directa. En 2013, los neoanarquistas recuperaron en la UNAM el auditorio "Che" Guevara, del que habían sido expulsados. Estos grupos no buscan negociar con ninguna autoridad, niegan la política porque la consideran espuria, dicen que el poder no le pertenece a la gente, sino al capital, por lo que el poder no se debe tomar, 
sino que hay que destruirlo. Sus actos se consuman en sí mismos. Tienen el presente como horizonte.

El autor constata que el neoanarquismo ha ido en aumento en el mundo. Profundiza en la postura neoanarquista que se puede sintetizar en el cuestionamiento frontal al modo de ser de la sociedad actual. Ante la grave situación de desempleo, exclusión, violencia y destrucción de la naturaleza por parte del capitalismo, el que se lance una bomba molotov contra espacios del poder o contra la policía es visto por estos grupos como un acto liberador. Para el autor es lamentable que la oposición al sistema no pueda articularse de una forma alternativa realista o en un proyecto utópico, mientras suceden explosiones sin sentido que implican espíritu de revuelta sin revolución.

El último capítulo trata el otoño del descontento. Se advierte que el desencanto juvenil responde a que los jóvenes se inscriben en la franja de edad más castigada por el paupérrimo crecimiento económico mexicano de las tres últimas décadas, a que son víctimas frecuentes de la extorsión policial y a que se han convertido en reserva de brazos del crimen organizado. El autor se pregunta por qué otra vez los jóvenes han tomado las calles, por qué algunos eligen las formas violentas de acción colectiva. Pasa por el movimiento \#YoSoy132. Considera que se trató de un movimiento efímero y atribuye la falta de consolidación a su escasa estructuración por su afán de horizontalidad y por la autonomía irrestricta de cada una de sus asambleas locales, y a que haya reducido su horizonte a la elección presidencial de 2012. Enfatiza que hubo deficiente coordinación del movimiento, escaso control sobre sus bases y falta de un núcleo de activistas medianamente profesionalizados. En los huecos que dejó, entraron en escena los anarquistas.

También aborda la disidencia magisterial frente a la reforma educativa, que provocó una fuerte resistencia. También trata someramente el fenómeno de las policías 
comunitarias y a las autodefensas ciudadanas. Alude al Movimiento por la Paz con Justicia y Dignidad. Se centra más en la movilización por Ayotzinapa, en la que destaca la enorme cohesión grupal y la capacidad de los normalistas de Ayotzinapa. Precisa que esa movilización sumó a los sujetos de las acciones colectivas de los tres últimos años: estudiantes, maestros y autodefensas, periodo en que se han juntado componentes pacíficos y violentos. Insiste en que no se pierda de vista que existe un efecto acumulativo de anteriores movilizaciones. Señala que la dimensión del acontecimiento empequeñeció a la ya de por sí desprestigiada clase política. Resalta que la base del movimiento fue el magisterio disidente de Guerrero, los padres y normalistas de Ayotzinapa y la policía comunitaria de Guerrero. El autor realiza un recorrido por las múltiples manifestaciones. Al referirse a la llamada verdad oficial, destaca que esta suscitó más repudio. Al principio, si bien crecieron las manifestaciones, también afloraron las acciones violentas. Apunta que presumiblemente un núcleo neoanarquista intentó quemar la puerta de Palacio Nacional. Al cumplir medio año de vigencia el movimiento, el autor percibió los efectos del desgaste.

El libro cierra con una compendiada conclusión. Rescata que como una forma de política popular los movimientos interpelan al poder presentando un conjunto de demandas que deberían ser atendidas. Acota que cuando el diálogo es fluido y las reivindicaciones legítimas (no buscan privilegios para un grupo, sino extender los derechos de todos), se fortalece la vida democrática de la sociedad. Precisa que salvo el caso del magisterio, donde el interés sectorial es discutible y se antepone al interés general, en los movimientos sociales analizados los reclamos del cumplimiento de las obligaciones del Estado, como los de proteger a los ciudadanos y dar cabida y aun ampliar los derechos humanos, se inscriben en la lógica democratizadora. Alaba que el movimiento 
\#YoSoy132 haya puesto en discusión la relación entre los medios de comunicación y la política. En los movimientos surgidos frente a la inseguridad, las respuestas del Estado han sido pobres y fundamentalmente se han ignorado las demandas sociales. Sostiene el autor que la movilización social puede contribuir a la democratización del régimen y a hacer explícito el inaceptable déficit de justicia que padecen amplias capas de la población. Al recapitular su visión en torno a la violencia social, recalca que esta es encendida por la desigualdad extrema y la injusticia.

Sus investigaciones llevan al autor a detectar un discurso antipolítico tanto en las movilizaciones guerrerenses como en muchas que afloran en la capital del país. Dicho discurso tiene la convicción de que la organización social por sí misma es capaz de generar estructuras de Gobierno. Pero el autor está convencido de que estamos ante una perspectiva limitada porque la forma de Gobierno así propuesta en el mejor de los casos funcionaría en sociedades homogéneas (como algunos pueblos indígenas), pero resulta inoperante en sociedades diversificadas y en centros urbanos donde coexisten intereses encontrados. Dejando de lado el antipoliticismo neoanarquista que responde a su propósito de acabar con toda política, el antipoliticismo juvenil actual lo ve el autor como una posición apartidista y que repudia todo lo que no sea horizontal. Esa ilusión antipolítica la ve como un lastre en la proyección del movimiento. Apelando a lo sucedido en la Primavera Árabe, sostiene que posiciones de esa naturaleza permiten que otros se apoderen de la dinámica del movimiento. Así se arrebata a la sociedad la oportunidad de acabar con la clase política corrupta y de edificar la indispensable política sobre bases nuevas.

Tal vez el autor estaría de acuerdo con la postura de unos brigadistas de la UNAM que han criticado las posiciones de los neoanarquistas, no por cuestiones de principios o ideologías, sino por los resultados de las acciones desatadas. 
Ven que los anarquistas tienen la idea de desangrar al sistema a partir de mil heridas pequeñas, por lo que optan por el actuar de pequeños grupos aislados que tomen por decisión propia acciones que algunos consideran "contundentes". Pero llaman la atención de que quemar camiones, patrullas o puertas, y "expropiar" comercios en beneficio de unos pocos, no disuelve el poder estatal y sí aísla a quienes realizan esto.

Los brigadistas aclaran que no se trata de estar contra la violencia por principio ni de omitir la necesidad de las acciones de fuerza para la lucha que se presenta, lo que cuestionan es la efectividad de esa ruta de acción para fortalecer el movimiento opositor. Recuerdan que esas tácticas ya fueron puestas en práctica desde hace años sin resultados a favor del cambio. Ponen por ejemplo que a partir del 01 de diciembre de 2012 hubo quienes entendieron que hacer avanzar la lucha implicaba el enfrentamiento constante con la policía, con la idea de que dichos enfrentamientos crearían una ola de acciones radicales. Pero los brigadistas apelan a los hechos y constatan que el resultado fue completamente opuesto, pues lo que se consiguió con esa táctica fue el aislmiento, la división interna, la baja en la participación y la represión indiscriminada; el resultado ha sido la detención de quienes emprendieron ese camino, que desgasta y desvía la fuerza del movimiento. Los brigadistas en un amplio alegato argumentan que nada indica que de seguir por ese camino se llegue a un resultado distinto (Los brigadistas-UNAM, 2014).

Los jóvenes anarquistas que conozco en Jalisco rechazan esos métodos con el argumento de que no hay que colocarse en los espacios ni en los tiempos del poder, sino construir autonomía al margen del capital y del Estado. En la revista del militante peruano Hugo Chávez, Lucha Indígena (en concreto en su número ciento doce, de diciembre de 2015, en la página 2) se llama la atención sobre que en Perú se 
conocen el terrorismo de arriba y el terrorismo de abajo, que se impulsan a sí mismos, se alimentan entre sí dañando al pueblo oprimido. Se precisa que ese terrorismo de abajo es practicado por gente indignada contra lo injusto del sistema de opresión, pero que no sirve para extinguirlo, sino que es usado por el sistema para reforzar la opresión en nombre de defensa contra el terrorismo. Apunta que es falso que la acción de unos cuantos inspire al pueblo a levantarse contra el poder, sino que lo amedrenta y en cambio el poder opresor usa eso mismo para comportarse con más violencia en contra del pueblo. Se llama a que, en cambio, se impulse la acción colectiva en la forma en que las colectividades populares lo decidan.

Puede haber cierta concordancia del libro de Illades con algunas posiciones de Franck Gaudichaud expresadas en el prefacio del libro colectivo América Latina. Emancipaciones en construcción, en donde el autor contrapone las posturas de quienes dicen que no hay que tomar el poder y los que defienden que se tiene que hacer. Para los primeros, la toma del poder termina con una izquierda tomada por el poder. Aducen lo que ha sucedido con los Gobiernos llamados "progresistas" en América del Sur, que han sido criticados duramente por movimientos sociales porque se han plegado a la lógica extractivista. Gaudichaud anota que los caminos de emancipación son muy sinuosos, que los aparatos de poder de las oligarquías son sólidos, reslientes y feroces cuando es necesario, pero sostiene que transformar las relaciones sociales de producción y desbaratar las dominaciones de raza y de género en las sociedades de América Latina es una dialéctica que tendrá que partir desde abajo y a la izquierda, desde la autonomía, pero siempre en clave política y no desde un ilusorio cambio sin toma del poder.

Gaudichaud critica la ilusión de la construcción de una pluralidad de autonomías sociales sin proyecto político común, sin un mínimo centralizado. Acepta que hay muchas 
experiencias en torno a cambiar el mundo, las cuales son contradictorias e incluso divergentes, algunas aisladas, muy localizadas, otras institucionalizadas o dependientes del Estado. Se pregunta cómo emprender una transición poscapitalista y ecosocialista, cómo reconstruir sentidos comunes, hegemonía cultural y una izquierda anticapitalista desde y para el pueblo, y cómo evitar forjar ilusiones en torno a pequeños grupos de afinidades cerrados sobre ellos mimos.

Lo que no se puede negar es que históricamente todavía no se ha dado el caso de que desde el Estado se pueda lograr un cambio que corresponda a las pulsiones del abajo social. No habría que desdeñar los esfuerzos que se empezaron a reforzar desde agosto de 2015 en México, cuando el magisterio disidente inició un proceso de reflexión con otros actores y movimientos, incluidos los padres y normalistas de Ayotzinapa, hacia un nuevo esfuerzo nacional unitario desde la dinámica, agenda y visión de los movimientos sociales. En octubre llegaron a un consenso que empezaron a informar y consultar con otros movimientos y espacios civiles y sociales. Habría que valorar las búsquedas de grupos autonomistas que van en el sentido de no dar ni una lucha aislada más, y los llamados zapatistas, para conseguir una unidad que no tenga que pasar por direcciones burocráticas.

En la bibliografía, Illades cita a Castells, en concreto su libro Redes de indignación y esperanza (la primera edición de 2012), pero no se ven reflejadas sus posiciones en los análisis. En particular en la segunda edición, que tiene casi la mitad de material nuevo y que fue publicada en 2015, Castells apunta que en la actualidad las instituciones no tienen legitimidad, y que la tecnología, los migrantes y los movimientos están moldeando la nueva era. Acota que los jóvenes salieron a las calles, pero que también están en las redes cibernéticas, que hay un cambio en las mentes y los corazones ligado a los movimientos sociales, lo cual implica que pueden acabarse algunas manifestaciones específicas,

\section{6}


y pone por ejemplo que los ocupa estadounidenses parecerían haberse esfumado porque las ocupaciones físicas de un espacio tienen límites, pero que en las movilizaciones que han seguido se encuentran los ocupa de otra manera. Es decir, cambian las formas de los movimientos, pero la dinámica producida por el cambio de mentes es más duradera. El libro de Illades en diálogo con otros textos puede suscitar muchas discusiones.

Lo que queda es recomendar ampliamente la lectura, el estudio y la discusión de un libro que aborda temáticas desde una óptica original y con una buena factura.

Los brigadistas-UNAM (19 de noviembre de 2014). Sobre la Bibliografía continuidad de nuestro movimiento. Recuperado de: http:// www.rebelion.org/noticia.php?id= 192186 